\title{
USING DIGITAL STORIES TO EXPLORE FOUR FINAL-YEAR STUDENT'S COLLIDING WORLDVIEWS AND HOW THIS IMPACTED THEIR CLASSROOM PEDAGOGY
}

\author{
Janet Condy, Heather Phillips and Chantyclaire Tiba \\ Cape Peninsula University of Technology, South Africa
}

\begin{abstract}
As contexts in schools and higher education become increasingly more diverse, engagement with human differences and different knowledges becomes essential. Institutions need to change their practices to respond to the different needs of learners, as well as valuing their knowledges and prospective teachers need to better equipped for these experiences. Hence, the purpose of this paper is to explore the intersectionality of four final-year students colliding worldviews within a digital story project and how, this experience supported, or not, their own classroom pedagogies. Through the use of the pedagogy of discomfort, we argue that this intentionally initiated module of using digital storytelling influenced these four learners to confront their colliding worldviews, identify their strengths and challenges. They all reflected on how this process had encouraged them to become more self-reflective thinkers in their own lives, those of their peers and their learners.
\end{abstract}

\section{KEYWORDS}

Classroom Pedagogy, Colliding Worldviews, Digital Storytelling, Pedagogy of Discomfort, $21^{\text {st }}$ Century Classroom, Higher Education Institution

\section{INTRODUCTION}

The purpose of this paper is to explore the intersectionality of four final-year students colliding worldviews within a digital story project and how, this experience supported, or not, their own classroom pedagogies. In this way, the convergence of both these advances in educational psychology and computing, impacted the educational arena and especially the students in this final-year course of a Higher Educational Institution (HEI) that prepares teachers in South Africa.

This innovative research project was anchored in a compulsory subject called Professional Studies for final-year students, in 2017 and 2018 with 106 and 86 students respectively. The majority of students came from working class backgrounds and would have been classified by the Apartheid government as Coloured and African. Although these terms are rejected by the authors, they are used normatively by the student population (Gachago, Clowes \& Condy, 2016).

This module was developed in response to the Department of Education's policy to prepare future teachers for diverse classrooms, to provide competent and responsible qualified beginner teachers (Department of Education, 2001). The Minimum Requirements for Teacher Education Qualifications (Department of Higher Education and Training 2011, pp 4) stress that teaching is a complex activity that requires teachers to integrate and apply knowledge and respond to different contexts. Condy, Green and Gachago (2019) state that as contexts in schools and higher education become increasingly more diverse, engagement with human differences and different knowledges becomes essential. Prospective teachers need to be well equipped for these experiences. This is confirmed by Bozalek and Zembylas (2019, pp 9) who state that institutions need to "change their practices to respond to the different needs of learners, as well as valuing the subjugated knowledges that students bring with them." 
The main aim of this research project was to create a constructivist learning environment where the students would be challenged to teach a decolonised curriculum, by foregrounding disrupting colliding worldviews and understanding stereotypical views of difference. The researcher considered the $21^{\text {st }}$ century deep learning competencies necessary for the Fourth Industrial Revolution; to live and survive in a rapidly changing world and how to deal with the complexities and ambiguities found in many South African classrooms (Gravett, 2019). Hence the research question became: How did the digital storytelling project, with the focus on colliding worldviews, impact four students pedagogical classroom practices?

\section{BACKGROUND AND LITERATURE REVIEW}

In South Africa 78\% of our Grade 4 children are not able to reading for meaning (Howie, Combrinck, Roux, Tshele, Mokoena \& Mcleod Palane, 2016). It is stated in the 2016 PIRLS that our learners could not retrieve basic information from the text to answer the simplest questions. When these learners arrive at HEI's, together with the present technological world, they lack the motivation to read stories and improve their own reading and writing skills, despite signing up to be trained as teachers. Stories are fundamental to develop human communication, learning by analogy rather than direct learning and higher order thinking (Ribeiro, Moreira \& Pinto da Silva, 2016, pp 182). Hence the idea of developing a multi-modal approach to this course by integrating a digital storytelling module with mixed groups, a trained facilitator, taught the students how to share their valuable stories, write, organise, cooperate and collaborate their colliding worldviews. Graham (2002) would call these experiences of students coming together to help and support each other a relational worldview.

\section{DIGITAL STORYTELLING}

For generations, the oral storytelling tradition has been used as a tool for the transmission and exchange of values and knowledge because it is a powerful and a natural form of communication (Smeda, Dakich, \& Sharda, 2014). Over the last decade, with the increased use of hardware and software systems available today, the dissemination of stories have changed. Today digital stories can be seen as the merging of traditional stories with the more modern use of multimodal technology used more widely as a pedagogical tool in higher education.

Typically a digital story is a short, personal, narrative of only 3-5 minutes long (Lambert, 2009) combing voice, image and music (Benmayor, 2008), integrating different literacies to engage and motivate students (Ribeiro, Moreira \& Pinto da Silva, 2016, pp 183). Technology is more effective when used as part of a broad educational improvement agenda (Pitler, 2006). In this particular research project the digital stories were purposefully used to disrupt students uncritical approach when reflecting on dominant worldviews (Gachago, Clowes \& Condy, 2018). Coventry (2008, pp 207) observes, that "Working in multimedia brings something to the student's learning that would otherwise not be possible: speaking and explaining through relatively unfamiliar modes of communication helps enforce a deeper engagement with ideas".

During the two-month teaching module, the researcher took the students through a carefully structured approach of constructing their own digital stories (Kajder, Bull \& Albaugh, 2005), using all the elements of digital storytelling to reflect on their colliding worldviews. Students worked in purposively arranged groups so that they shared with people with whom they would not normally have collaborated. This constructivist approach of learning through using authentic contexts, including the social paradigm is one of the most influential educational contexts in the $21^{\text {st }}$ century (Smeda, Dakich, Sharda, 2014).

\section{WORLDVIEWS}

Politicians, educationists and economists in South Africa are constantly struggling to find out why our literacy and numeracy rates are consistently low in both international and national assessments. One aspect that has not been researched is the fact that as human beings we need to make sense of our lives, our biases, 
stereotypes and prejudices which gives rise to our worldviews (Tiburt, 2010). Education does not occur in a vacuum. In a $21^{\text {st }}$ century classroom, a teacher may expect to find many worldviews being expressed and encountered, it is essential that teachers need to be aware of and knowledgeable about a range of worldviews. In any society there will be dominant worldviews held by the majority of the community. Alternative worldviews do exist that may be different, unconventional, marginal or complementary to the dominant worldview. Some may provide a purpose and a direction in life, provide values, inform decision making and suggest standards of conduct, and some may even be in conflict to each other. Hence, Tiburt (2010, pp 180) suggests that in the "health profession, as challenging worldviews may be, educators must learn to acknowledge their complexity so that trainees can more effectively communicate with patients and populations who may not share their own worldview."

Tiburt (2010) believes worldviews are metanarratives or sets of beliefs and assumptions that are deeply embedded and largely implicit in how cultures interpret and explain their experience. Hart (2010) extends this belief by saying that worldviews are described as mental lenses that are entrenched ways of perceiving the world. They are intuitively, unconsciously and uncritically developed over time throughout a person's life through socialising and social interaction, and are often taken for granted. Worldviews can be cognitive, perceptual and affective maps that people continuously use to make sense of the social landscape and to find their way to whatever goals they seek (Hart, 2010).

Children are not born with a worldview. Parents or significant others, society and culture, together are important facilitators in developing a child's emergent worldview. A worldview can be either communal as well as personal (Fisher, 2012) as shared vision often promotes community, where there is a strong sense of community, tied together by familial relations and the families commitment to it (Graham 2002). Individuals enjoy freedom in self-expression because it is recognised by the community that individuals take into consideration and act on the needs of the community as opposed to acting alone.

A counter argument exists which suggests there is growing concern that it is not necessary to have a worldview which includes a systematic codified belief system. Fisher (2012) claims that disparate and eclectic presuppositions from a variety of worldviews can fit together, despite apparent contradictions, and may be able to answer life's questions. When systematised and codified worldviews become extreme they move towards fundamentalism. Where this type of worldview refuses to entertain and evidence contrary to his or her worldview.

\section{THE PEDAGOGY OF DISCOMFORT}

Boler (1999) in her book, Feeling Power: Education and Emotions, first introduced the concept of the 'pedagogy of discomfort'. She explained how students, during the Persian Gulf war, disengaged with media, denying the war took place, with the resulting emotions of powerlessness and numbness. To survive these injustices, and an inability to effect change, students became desensitized, which reinforced their numbness. The students were silenced, which lead to self-hatred and distanced them from human connections, increasing their sense of isolation. This sense of self-imposed isolation not only occurs at an individual level but to the broader societal level, which manifests as identity politics, power relations and fear. Taleb (2010, pp 4) posits that when individuals face knowledge that is fragile and contradicts the beliefs they hold as true "... they may experience discomforting emotions such as guilt, fear, anger, anxiety and deep emotion."

Bheekie and van Huyssten (2015) explain how a dominant culture reinforces emotions that are either acceptable or unacceptable and how HEIs accept these biased viewpoints as normative. Twenty-five years after South Africa's transition to democracy, the constitution provides for a more social just society where issues of diversity such as; race, language, gender, religion, culture and socio-economic status, are still very much alive amongst the student population at the HEI where this research project took place. This project encouraged the participants to engage in critical thinking that explored issues of power in dominant worldviews, habits, practices and knowledge. A classroom environment was created whereby the students explored the messiness of power relations and "to stay away from neat unquestioned stereotypes" (Condy, 2015, pp 145). 


\section{RESEARCH APPROACH}

A case study approach was used within a critical interpretive research paradigm for the researcher to explore four final-year student's colliding worldviews and how this impacted their classroom pedagogy. This design helped describe and explain their real-life phenomena and to develop a true reflection of what was happening by considering the context within which it occurred (Yin, 2003, pp 1).

Qualitative data were collected from two sources: in the form of digital stories in 2017 and 2018 and a focus group interview in 2019. The information gathered from these stories and the one focus group interview helped the researcher to gain insights through "... subjective understanding ..." of how these students and managed their colliding worldviews and how these experiences helped them in their own teaching experiences (Henning et al., 2007, pp 3).

The four students who were purposively selected to be part of this study were involved with postgraduate studies and were available to be interviewed. At the time of the interviews, two students had been teaching for 6 months and two had been teaching for 18 months. The students' names will be kept anonymous: named as NK, SM, MN and LT. All students and the university signed ethical clearance for this research.

\section{FINDINGS}

Four vignettes present four students' colliding worldviews and how they rose above their circumstances. A short discussion on each vignette follows. To conclude this section, the results of the interviews and how this project influenced their teaching will be discussed.

Vignette 1

Debt almost killed me, my being, and my values. It almost destroyed my future.

Between the period of my matric year and my first year of varsity, I found myself in adjacent walls tall enough to suffocate me, ending my dreams. A corner that was subconsciously built by my parents due to their bad financial decisions.

Deep down in my heart I knew a parent would never intentionally kill their children's dreams or life desires but by allowing debt into our lives, they simultaneously allowed poverty to creep in like darkness tangling innocent light, with no hope of escaping the torture and pain of poverty in our lives.

The void and smell of poverty impregnated my heart with anger, the un-intentional knife caused by the people I loved so dearly had slit through my being and bought pain in my comfort zone, with tears racing down my cheeks each time the thought of the situation at home crossed my mind with unanswered questions Was it necessary to sacrifice our happiness?

If only my mother never built that house in Eastern Cape...

If only my father never took that loan...

She concluded her digital story by stating that:

Wearing a smile and confidence was my key to success, my vulnerability fed my hunger to success because through the series of unintentional poverty I had three choices, to give in, to give up or to Discussion give it all I got. And I chose giving it all I have..

NK grew up strangled by her parents relational worldview culture; who consciously made decisions, probably influenced by the community, putting her family into deep poverty, torture and pain. She knew she had to act alone to rise above her and her families colliding worldviews.

Vignette 2

Days came and passed as I wondered when that day will come, where my long waited for expectation will be fulfilled. I was young and vulnerable but at the same time, I was socialised that 1 will grow up and be a woman and have my own home and children. I had a view that even though I was younger and uneducated my mother would respect my choices. However, she had a single story about what it meant to be a mother. I was at the age of 19 when I got engaged. Our relationship turned sour when I fell pregnant and had a baby. 
She abandoned me because she did not approve of my relationship. Regardless of all her promises to love us unconditionally, she did not keep the promise. Was it a collision of world views? My mother expected me to stay out of school and get a job and further my studies but I thought marriage was the right thing for me at that time. My view was it is okay to get married first and then go back to school later. She wanted what she thought was best for me but it was my choice to make a decision.

SM completed her digital story by stating:

I grew from this experience and learnt how to forgive, be open minded, allow people around me to be imperfect and build relationships that are none power based. I gained a voice to share my experience with my mother and love her more, show her compassion. Of all I learnt that it is okay to be vulnerable for I know I AM ENOUGH!

Discussion

SM lived in a community that shared a deeply embedded implicit worldview, often taken for granted, that mothers helped their daughters with their children. She intuitively believed that although she was to have a baby before being educated, her mother would support her child. In this case the mother chose consciously not to abide by this codified belief system which developed into a clash of ideologies.

\section{Vignette 3}

Life without my mum was not easy. I thought I will be with her for the rest of my life. Her passing away changed everything in my life. I became rebellious and opted to drink alcohol and do drugs. I thought this route would work for me, but it didn't work at all. The consequences of doing drugs were divisions within the family. Our family views collided. Alcoholics supported my behaviour because in my culture men must drink and marry. I was following the footsteps of my forefathers, and I should not be ashamed. Other relatives were against the strategy that I used to deal with my mother's death.

Some had stereotypes about orphans; they believed that orphans end up being alcoholics and failures. Some of my family members lose hope on me especial in the side of education, assuming that I won't be successful without my mother.

As days passed I realized my life was falling apart. I lost almost everything that my mother had left behind. My siblings were angry with me. Eventually I gave up alcohol and drugs and decided to go back to school.

MN completed his digital story by declaring:

Fortunately, I got a part-time job in the university in order to get something to eat and books. I told myself that the death of my mother is not the end of my future and dreams. Now I am doing my Discussion

final year Bachelor in Education, and I'm going to be a teacher.

Although in MN's culture there was a strong sense of community where men must drink and marry, he, personally, experienced a colliding worldview when he chose drugs to mourn the death of his mother. $\mathrm{He}$ was not acting on the needs of the community: rather he chose to act alone against his cultural deeply rooted worldviews. After hearing they believed he was a failure, he consciously and critically decided to change his worldview and worked hard at changing his landscape to find his way to achieve his goals.

\section{Vignette 4}

Born and bred in the valleys of the Eastern Cape residing with my mother, father and siblings. Our mother was our pillar of strength, as she 45 was the breadwinner, there was no one to support her in raising us. She was however, not a single mother.

In the outside world I felt isolated and small, my ego was bruised my self-esteem was crushed. I sometimes wished I wasn't born, regretting to be part of my own family and friends. I felt worthless in society, since we had nothing and we were underestimated.

School was a knotty experience and obscure to society. I was never present in school excursions due to financial problems that we had. In class, I felt continuously anxious; the only thought that I pondered is "I can't wait for lunch time so that I can get a slice of that delicious jam sandwich." 
A discreet and cautious attitude started arousing my personality and character, such that I avoided to be seen by people. I had to deal with the assumptions people concluded about my life. No one had an idea what I was going through and no one showed interest as to why I was discreet and shy.

LT narrated at the end of her digital story that:

My vulnerability and persevering through my trials and tribulations made me believe that poverty and my background will never determine my future. Instead I will keep rising above my circumstances to be the human I am today, because I believe that I am like a lighthouse that has Discussion never been shaken by heavy storms

In LTs family, poverty was the commonly held worldview, but this differed from the community in which she lived and where she was educated. Within her community the core worldview held a belief that learners should be able to attend excursions and be socially involved - this was her colliding worldview when she found herself alone.

\section{INTERVIEWS}

When analysing the focus group interview data about how the digital storytelling project explored the students colliding worldviews, and how this experience impacted their classroom pedagogy, it became evident that the main theme was that they gained a greater awareness. They became more self-reflective within their own thinking and their own lives; they were more aware of how to deal with their learners, and how to be aware of working with their staff members.

The students reflected that this digital storytelling process provided them with a greater sense of awareness to themselves, their learners and their teaching environment. One student narrated that this process of exploring ones colliding worldviews was an empowering process because you have got to question things: "it helped me to change the way I view the world because now I believe every individual has a story to tell ... that we can be different as people but we have the same circumstances that we go through ..." Another student added that: You get to look at yourself and look at the stereotypes that you've got, the biases... the expectations you have. However, one student cautioned: "I must be aware of those stumbling blocks you see, there are difficulties that I'm going through at work - it's a sort of an awareness thing ..."

One student confronted the idea of a worldview as a given construct saying: "I want to disagree with the fact that it [a worldview] is a given ... views actually mutate ... It is given at a certain age perhaps when you are still growing up. What your parents teach you is what you take. But then as you grow older you start making your own decisions - like you can change those views, you can question them, critique them ... I think views change based on circumstances or situations and the moment you start realising them you start being aware of them you will constantly critique the way you view your thinking.... You realise you have a right to confront people when there's biases and stereotypes..."

One student shared that: "it gave me strength like to be the person I am, that will stick to my morals and values because I feel like I am the role model to my learners, so I have to be true to myself."

Not only were the students more self-aware but this process encouraged a more awareness of working with their learners:

like its personal issue so we don't have to judge or punish. You must just speak with the learner asking why are you behaving like this. So that you can get more information so you can be aware of what is happening to that particular learner.

I use it a lot with my children because when we teach, we expect children to respond in a certain way and at the same time, you find the school has got expectations about the learners. I look at my learners and then I'm like, I don't know what this child is going through, ... but then I can never judge the learner ... so that has taught me a lot.

I think one thing that it has taught me is, to not judge my learners.

it actually helped me to understand that people and even children go through a lot of things ... seriously traumatic things... and that could be a barrier to teaching and learning. 
One student explained that this process helped her to constantly motivate her learners: "it has also transferred in a sense that, you as a teacher like you need to constantly motivate ... So now you need to constantly tell children that they are the ones being educated. So it also helped in that sense."

For the one student whose parents made the decision to put the family into financial stress, she shared that this process: "empowered me in a sense that ... I'm more aware of my financial expenditures, so for me to learn from that ... in providing a stable future for my child and for myself. I know that I need to be careful with a lot of things because otherwise I will find myself back in that situation. In the classroom - yes because for instance with casual money you find that some children cannot pay casual money." She proceeds to provide options of payment to her learners so "that you do not have to stress. That's how I apply my learning."

Now that these teachers are teaching in schools, this process has taught them to be more aware of their teaching environment:

I must be aware of my surroundings, looking at the staff, that I'm working with, it prepares me ... it is very important to understand people, you see, even their behaviour. Academically or like here at work, it prepares me that it gives me strength ... because there are stumbling blocks ...

... it has a sense of greater awareness not only for yourself but for what's happening around you because from that digital story, you were able to see that people have burdens within and they're not just going to show you, so in the teaching profession that also happens because yes in varsity it was peers but now it is your colleagues ...

The whole process has taught me to be confident enough to educate my learners that we are different - we must not let our backgrounds become the barriers to our teaching and learning - we are all human at the end of the day.

\section{CONCLUSION}

Through the intentionally initiated influences of this module, framed within the pedagogy of discomfort, which set out to address evolving learning processes with supporting pedagogical applications, these four students developed socially, emotionally and professionally. As a result of collaboration, reflection and interpersonal communication skills, these students have been motivated to use multimedia to confront their own biases and stereotypical worldviews and to consequently, improve their own pedagogical practices.

Teachers today require more complex and different skills to be prepared to engage, address and challenge the critical and dominant worldviews, in our educational arena facing our diverse learners. They need to be aware of the interconnectedness between fast-changing different knowledges and professional practices that will result in transforming our learners in the $21^{\text {st }}$ century. The researcher agrees with Tiburt (2010, pp 180) who suggests that educators should learn to acknowledge the complexity of student and learner's worldviews so that we can more efficiently communicate with them. The pedagogy of discomfort created a safe space for this transformation to occur where all four students agreed that this process of writing and reflecting on a particular colliding worldview and putting it into a digital story, was an uncomfortable experience. Yet six months to a year later, they shared how much they had learnt from sharing their vulnerabilities and that they have been able to inculcate these learnings into their own personal lives as well as their pedagogical practices.

All four students willingly shared their taken-for-granted, unconscious personal and community worldviews and the discomfort of these traumatic experiences. At the time of these ideological clashes none of the students were able to change anything. However a few years later, when reflecting on this experience, during the making of their authentic digital stories, they shared how this experience created many different personal and pedagogical opportunities and how much stronger they had all become to rise above their circumstances.

The findings of the focus-group interviews suggest that this project, heightened the students awareness of their own colliding worldviews which in-turn encouraged them to become more metacognitively aware of their own worldviews as well as learning valuable pedagogical approaches of how to manage their peers, learners and be a role model in their communities. Some students reflected on how they could now identify their own 'stumbling blocks' and those found in their peers in the staffroom and now know they have to be 
approached with caution and care. The researcher argues that these students now hold strong views on listening to their learners, motivating them, exploring their worldviews and how not to judge. They have become more passionate about confronting people who hold unconvincing biases and stereotypical worldviews.

\section{REFERENCES}

Benmayor, R. (2008). Digital storytelling as a signature pedagogy for the new humanities. Arts and Humanities in Higher Education, 7(2): 188-204.

Bheekie, A. \& van Huyssteen, M. (2015). Be mindful of your discomfort: An approach to contextualized learning. International Journal of Research on Service-Learning and Community Engagement, 3(1) Retrieved from http://journals.sfu.ca/iarslce.

Boler, M. (Ed.). (1999). Feeling power. Emotions and education. New York: Routledge.

Condy, J. (2015). The constructions and transformation of pre-service teacher's individual, social and professional identities during a digital storytelling module. In J. Condy, (Ed.). Telling stories differently: Engaging $21^{\text {st }}$ Century students through digital storytelling (pp. 141-151). Cape Town: SUN Media.

Condy, J., Green, L. \& Gachago, D. (2019). Exploring being human today: a journey to equip prospective teachers in South Africa to engage critically with diversity. In G. Maré (Ed.), Race in education (pp. 41-68). Cape Town: Sun Press. ISBN: 978-1-928357-84-1.

Fisher, B. J. (2012). Exploring worldviews: A framework. The TEACH Journal of Christian Education, 6(1): Retrieved from https://research.avondale.edu.au/teach/vol6/iss 1/11.

Gachago, D., Clowes, L. \& Condy, J. (2018). 'Family comes in all forms, blood or not': disrupting dominant narratives around the patriarchal nuclear family. Gender and Education, 30(8): 966-981. Retrieved from https://doi.org/10.1080/09540253.2016.1259464.

Gravett, S. (2019). Industry 4.0 is being taken seriously. Mail \& Guardian: 18 January 2019.

Hart, M. A. (2010). Indigenous worldviews, knowledge, and research: The development of an indigenous research paradigm. Journal of Indigenous Voices in Social Work, 1(1):1-16.

Henning, E., van Rensburg, W. \& Smith, B. (2007). Finding your way in qualitative research. Pretoria: Van Schaik.

Howie, S., Combrinck, C., Roux, L., Tshele, M., Mokoena, G. \& Mcleod Palane, N. (2017). Progress in international reading literacy study 2016: South African children's reading literacy achievement. Pretoria. Centre for Evaluation and Assessment.

Kajder, S., Bull, G., \& Albaugh, S. (2005). Constructing digital stories. Learning \& Leading with Technology, 32(5), $40-42$.

Lambert, J. (2009). Where it all started: The centre for digital storytelling in California. Story circle: Digital storytelling around the world, California: Wiley-Blackwell, pp 79-90. https://www.google.co.za/url?sa=t\&rct=j\&q=\&esrc=s\&source=web\&cd=2\&cad=rja\&uact=8\&ved=2ahUKEwiwrdG TmILjAhWVSBUIHQ1NC

Pitler, H. J. (2006). Viewing technology through three lenses. Principal, 85(5):38-42.

Prebel, J. (2016). Engaging a "Pedagogy of Discomfort": Emotion as critical inquiry in community-based writing courses. Composition Forum, 34 Retrieved from http://files.eric.ed.gov/fullte4xt/EJ1113429.pdf.

Ribeiro, S., Moreira, A. \& Pinto da Silva, C. (2016). Digital storytelling: Emotions in higher education. In Competencies in teaching, learning and educational leadership in the digital age. Retrieved from https://www.research gate.net/publication.288434000. ISBN: 978-989-8533-23-4.

Smeda, N., Dakich, E. \& Sharda, N. (2014). The effectiveness of digital storytelling in the classrooms: A comprehensive study. Smart Learning Environments, 1(6) doi 10.1186/s40561-014-0006-3.

South Africa. National Department of Higher Education and Training. (2015). The Revised Minimum Requirements for Teacher Education Qualifications (MRTEQ). Pretoria: Government Gazette 553 (38487).

Taleb, N. N. (2010). The black swan: The impact of the highly improbably. London: Penguin Books.

Tiburt, J. C. (2010). The role of worldviews in health disparities education. Journal of General Internal Medicine, 25(2):178-181.

Yin, R. K. (2003). Case study research: Design and methods. Thousand Oaks, CA: Sage 